\title{
Impact of dental caries on oral health related quality of life among preschool children: perceptions of parents
}

Mina Pakkhesall, Elham Riyahi ${ }^{2}$, AliAkbar Naghavi Alhosseini ${ }^{3 *} \mathbb{C}$, Parisa Amdjadi ${ }^{4}$ and Nasser Behnampour ${ }^{5}$

\begin{abstract}
Background: Childhood dental caries can affect the children's and their parents' oral health-related quality of life. The aim of the present study was to evaluate the impact of oral and dental health conditions on the oral health-related quality of life in preschool children and their parents.

Methods: In this descriptive-analytical cross-sectional study, samples were selected from children 3 to 6 years old enrolled in licensed kindergartens using "proportional allocation" sampling. Then, the parents of the children were asked to complete the Early Childhood Oral Health Impact Scale (ECOHIS).

Results: In this study, 350 children aged 3 to 6 years were evaluated with a mean age of 4.73 years. The mean $\mathrm{dmft}$ index (decayed, missed, and filled teeth) was 3.94 \pm 4.17 . The mean score of oral health-related quality of life was $11.88 \pm 6.9$, which $9.36 \pm 5.02$ belongs to the impact on children and $2.52 \pm 3.20$ to parents' impact.

Conclusions: The mean score of ECOHIS increased with the dmft index increase in children, indicating a significant relationship between the $\mathrm{dmft}$ and ECOHIS score. These outcomes can be used as proper resources to develop preventive policies and promote oral health in young children.
\end{abstract}

Keywords: Quality of life, Oral health, Child, Parents

\section{Background}

According to the World Health Organization, the quality of life is defined as "a person's perceptions of their position in life according to their culture, goals, expectations, standards, and priorities". Therefore, it is subjective and not observable by others and is based on the person's understanding of different aspects of life. Therefore, the quality of life of each individual is influenced by their conditional characteristics and social, cultural, and environmental status $[1,2]$.

Today, health is considered to be a holistic concept that encompasses many aspects, such as physical,

\footnotetext{
*Correspondence: a.a.nagavi@gmail.com

${ }^{3}$ Dental Research Center, Orthodontics Department, School of Dentistry,

Golestan University of Medical Sciences, Gorgan, Iran
}

Full list of author information is available at the end of the article emotional, social, and spiritual health. Oral health is also defined as "a comfortable and functional dentition that allows individuals to continue their social role." Therefore, oral health is more than the absence of dental caries or gum disease or even having healthy teeth [3]. Oral health is one of the determinants of quality of life. Overall, the craniofacial complex allows us to talk, laugh, kiss, touch, chew, swallow, and cry. Oral and dental illnesses also cause restrictions in the school, work, and home environments; consequently, hours loss of school and work attendance. Poor oral health can also affect the quality of life. Experiencing pain, tolerating dental abscesses, difficulties in chewing and swallowing, feeling embarrassed about teeth shape or missing teeth, and tooth discoloration or decay may affect daily life and people comfort. In recent years, many studies have been conducted on the impact of

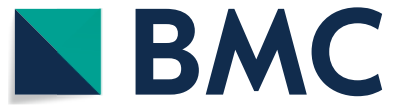

(c) The Author(s) 2021. Open Access This article is licensed under a Creative Commons Attribution 4.0 International License, which permits use, sharing, adaptation, distribution and reproduction in any medium or format, as long as you give appropriate credit to the original author(s) and the source, provide a link to the Creative Commons licence, and indicate if changes were made. The images or other third party material in this article are included in the article's Creative Commons licence, unless indicated otherwise in a credit line to the material. If material is not included in the article's Creative Commons licence and your intended use is not permitted by statutory regulation or exceeds the permitted use, you will need to obtain permission directly from the copyright holder. To view a copy of this licence, visit http://creativecommons.org/licenses/by/4.0/. The Creative Commons Public Domain Dedication waiver (http://creativeco mmons.org/publicdomain/zero/1.0/) applies to the data made available in this article, unless otherwise stated in a credit line to the data. 
oral health on the quality of life [4], especially in young children, because dental caries and traumatic dental injuries (TDI) are the most common problems affecting young children in both developed and developing countries worldwide $[5,6]$.

Dental caries and dental injuries during childhood may have negatively impact on the oral health-related quality of life of the children and their parents [7-9]. Many of this caries are also left untreated in this age group, which usually affects the weight, growth, quality of life, and cognitive development of the children and may result in hospitalization and emergency dental visits [5]. "Early childhood caries" (ECC) is one such common dental health condition seen in infants and toddlers around the world [10]. Children with untreated early childhood caries (ECC) have significantly poorer oral health related quality of life than children without ECC [11]. Evidence also reveals that ECC results in loss of the workdays for parents to take care of their child or spending time and money in accessing dental care [8]. In addition, parents play an important role in the oral health status of children and in seeking dental care and therefore tend to express feelings of guilt when their child exhibits oral health problems and/or treatment needs [12].

Researchers have used various measurements to assess the Oral Health-Related Quality of Life (OHRQoL), a few of which are designed for children under the age of $6[5,13]$. These measurements are usually assessed through interviews with children who can speak and write or completed questionnaires by children or their parents. Currently, the Early Childhood Oral Health Impact Scale (ECOHIS) is one of the appropriate tools to assess the oral health related quality of life in children due to their inability to read and write $[4,14]$.

The questionnaire was initially designed by Pahel [15] and then translated and evaluated for use in other countries like France, China, Brazil, and Iran [15-19].

After translating the Scale into Persian, Dr. Jabbarifar et al. assessed the validity and reliability of the Persian version of the Scale using a questionnaire completed by 246 parents of children aged 2 to 5 years in Tehran and Isfahan. It was concluded that the Persian version of the ECOHIS was valid and reliable to assess the impact of oral health on preschool children's quality of life of with Persian-speaking parents [20].

Given the importance of patient-centered approaches to clinical decision-making in recent years and the attention paid to the oral health-related quality of life in dentistry, the present study was conducted to investigate the effect of oral health on the quality of life of preschool children and their parents in Gorgan. .

\section{Methods}

The present study was approved by the Research Ethics Committee of Golestan University of Medical Sciences (IR.GOUMS.1397.166) and performed entirely following the Declaration of Helsinki. All participants' rights were protected. Informed consent was obtained from parents before the study. Moreover, the data were handled anonymously and confidentially in all stages of the study.

\section{Study population and sampling}

The sample size was calculated at 330 preschool children, based on a 0.05 Type I and 0.2 Type II error rate. Also, $20 \%$ was added to compensate for possible losses, giving a total sample of 350 preschool children.

This cross-sectional descriptive-analytical study was conducted among 350 children aged 3-6 years selected from about 6000 children registered in the licensed kindergartens of Gorgan. Hence, the list of licensed kindergartens in three municipality districts of Gorgan was prepared. Then, according to the number of children in each municipality district's kindergartens, the number of children in each district was determined. Numerous kindergartens were selected randomly (allocating a number to each kindergarten and selecting random numbers).

Children aged 3-6 years whose parents could easily speak Persian were selected. Exclusion criteria were a history of systemic diseases or receiving specific medication. Parents who did not complete the questionnaires were also excluded.

In the first session, the aim of research was explained to kindergarten teachers. Then, demographic questionnaires were given to preschool educators and administrators as well as consent forms to be completed by parents. Demographic information included data on the child's age, gender, ethnicity, birth order, and parental level of education.

\section{Questionnaires and data collection}

In the next session, the parents completed the Persian version of the Early Childhood Oral Health Impact Scale. The questionnaire consists of 13 questions, classified into two sections: "impact on children" and "impact on parents". The first 9 questions of the questionnaire examine the impact of the children's oral health, including items such as eating, sleeping, and talking. The second section, "impact on parents", has 4 questions in 2 subscales: parents' concerns (2 questions) and parents' functions (2 questions).

Response options included "never", "hardly ever", "occasionally", "often", "very often", and "don't know" that received a score of 0 to 5 , respectively. A score for the missing items was imputed as an average of the remaining items for each section. Overall, the total score of this 
index ranges from 0 to 52 with a higher total score indicating more oral health problems and less oral healthrelated quality of life.

\section{Children's oral examination}

Clinical examinations were performed by the researcher to measure the dmft index (decayed, missed, and filled teeth) using dental examination tools (disposable dental mirror, dental explorer, sterile gauze, and mask) according to the World Health Organization criteria for the diagnosis of caries. Moreover, all of the oral examinations were performed by a single trained and calibrated researcher. Hence, only intra examiner reliability was determined. Thus the oral examination of 10 randomly selected subjects was repeated at two time points to determine intra examiner reliability. The Kappa coefficient value for intra examiner reliability was 0.87 which is interpreted as very good.

For clinical examination, the child was seated in a chair in front of a window, and a flashlight was used if there was insufficient light. Besides, another person previously trained by the project administrator recorded the codes for the dmft index in the oral health assessment forms (provided by the World Health Organization).

\section{Data analysis}

Data were analyzed by the SPSS software version 16 using mean, standard deviation, frequency, and percentage. Then the normality of the data was determined by the Shapiro-Wilk test. An Independent t-test was used for data with a normal distribution, and the Mann-Whitney test was used for data that did not have a normal

Table 1 Mean of dmft score and Impact on oral health-related quality of life according to independent variables

\begin{tabular}{|c|c|c|c|c|c|c|c|}
\hline \multirow[t]{2}{*}{ Variables } & \multirow[t]{2}{*}{$\mathrm{N}(\%)$} & \multicolumn{2}{|c|}{ dmft score } & \multirow[t]{2}{*}{$P$-value } & \multicolumn{2}{|c|}{$\begin{array}{l}\text { Impact on oral health- } \\
\text { related quality of life }\end{array}$} & \multirow[t]{2}{*}{$P$-value } \\
\hline & & Mean & SD & & Mean & SD & \\
\hline \multicolumn{8}{|l|}{ Gender } \\
\hline Boys & $189(54 \%)$ & 3.93 & 4.22 & $0.935^{*}$ & 11.27 & $6 / 60$ & $0.09 * *$ \\
\hline Girls & 161 (46\%) & 3.96 & 4.12 & & 12.59 & $7 / 22$ & \\
\hline \multicolumn{8}{|l|}{ Child's age } \\
\hline $2 \leq$ age $<3$ & $51(14 \%)$ & 1.94 & 2.28 & $>0.0001^{* * * *}$ & 8.21 & 4.87 & $>0.0002^{* * *}$ \\
\hline $3 \leq$ age $<4$ & $94(27 \%)$ & 3.10 & 3.48 & & 11.54 & 6.63 & \\
\hline $4 \leq$ age $<5$ & 104 (30\%) & 3.84 & 3.28 & & 12.88 & 6.68 & \\
\hline $5 \leq$ age $<6$ & 101 (29\%) & 6.07 & 5.23 & & 13 & 7.67 & \\
\hline \multicolumn{8}{|l|}{ Mother's education } \\
\hline Illiterate/ Elementary & $21(6 \%)$ & 8.05 & 5.35 & $>0.0001^{* * * *}$ & 13.85 & 6.62 & $0.001^{* * *}$ \\
\hline Secondary & $18(5 \%)$ & 6.38 & 3.36 & & 16.22 & 7.28 & \\
\hline Diploma & $91(26 \%)$ & 4.96 & 4.39 & & 13.35 & 7.62 & \\
\hline University & $220(63 \%)$ & 2.93 & 3.57 & & 10.72 & 6.33 & \\
\hline \multicolumn{8}{|l|}{ Father's education } \\
\hline Illiterate/ Elementary & $16(4 \%)$ & 6.87 & 4.47 & $>0.0001^{* * * *}$ & 15.81 & 8.19 & $0.004^{* * *}$ \\
\hline Secondary & $34(10 \%)$ & 6.35 & 4.82 & & 13.50 & 7.45 & \\
\hline Diploma & $84(24 \%)$ & 5.34 & 4.68 & & 13.20 & 7.21 & \\
\hline University & $216(62 \%)$ & 2.81 & 3.35 & & 10.81 & 6.40 & \\
\hline \multicolumn{8}{|l|}{ Ethnicity } \\
\hline Fars & $287(82 \%)$ & 3.60 & 4.03 & $0.002^{* * * *}$ & 11.78 & 6.93 & $0.783^{* * *}$ \\
\hline Turkmen & $33(9.5 \%)$ & 4.93 & 3.73 & & 11.96 & 7.06 & \\
\hline Sistani & $30(8.5 \%)$ & 6.16 & 5.16 & & 12.66 & 6.81 & \\
\hline \multicolumn{8}{|l|}{ Birth order } \\
\hline First child & $228(65 \%)$ & 3.83 & 3.98 & $0.457^{* * *}$ & 11.81 & 6.82 & $0.450^{* * *}$ \\
\hline Second child & 106 (30\%) & 3.97 & 4.54 & & 12.26 & 7.23 & \\
\hline Third child & $16(5 \%)$ & 5.43 & 4.21 & & 10.31 & 6.20 & \\
\hline
\end{tabular}

* Calculated by independent T-test

** Calculated by Mann-Whitney test

*** Calculated by Kruskal Wallis test

**** Calculated by analysis of variance (ANOVA) test 
distribution. $P$-values less than 0.05 were considered significant.

\section{Results}

In this study, 350 children aged 3-6 years with a mean age of 4.73 years were studied, of whom 189 (54\%) were male, and 161 (46\%) were female. Also, 228 children were first birth order, 106 were second birth order, and 16 were third or fourth birth order. In terms of ethnicity, 287 children were Fars, 33 were Turkmen, and 30 were Sistani.

The minimum and maximum dmft index of the primary teeth was 0 and 20, respectively with an average of 3.94 and a standard deviation of 4.17. It is noticeable that a higher percentage $(89.85 \%)$ of the $\mathrm{dmft}$ index was related to the decayed teeth (d) component in this study.

According to the results, there was no significant relationship between the mean $\mathrm{dmft}$ index and gender and birth order in the family. However, the mean dmft index had a significant relationship with ethnicity, child's age, and parents' education level $(P<0.05)$.

In addition, the results showed no significant correlation between the mean score of the oral health-related quality of life and gender, birth order in the family, and ethnicity. Nonetheless, the mean score of the oral health-related quality of life significantly correlated with the child's age and parents' education level $(P<0.05)$ (Table 1).

The mean score of the oral health-related quality of life was $11.88 \pm 6.91$ (range $0-33$ ); it was $9.36 \pm 5.02$ (range $0-25$ ) in the child impact and $2.52 \pm 3.20$ (range 0-16) in the parents' impact (Table 2).

According to the results, with an increase in the children's dmft index, the mean score of oral health-related quality of life increased, too (Table 3). This relation was more robust in the family impact compared to the child impact (Figs. 1, 2). It should be noted that an increase in the mean score of quality of life indicated a poorer oral health status.

\section{Discussion}

In the present study, the mean score of oral healthrelated quality of life was $11.88 \pm 6.91$ in preschool children of Gorgan, which is in agreement with a study by Amirabadi et al. [21] in preschool children of Zahedan $(10.94 \pm 7.69)$ and another study in preschool children of Babol (6.65 \pm 3.57$)$ [22]. Moreover, the results of a study by Sajjadi et al. in Kerman preschool children [23] showed that the ECOHIS score was $4.07 \pm 0.79$ for children and $3.28 \pm 0.83$ for their parents. Shaghagheian et al. study [24] reported an ECOHIS score of $19.46 \pm 8.42$ for preschool children in Shiraz. Discrepancies between our results and previous study can be explained by the use of different scores of the responses and analysis for ECOHIS score. In the present study, the scores of the responses according to the original questionnaire (ECOHIS) [15] ranged from 0 to 4 and thus, the total scores ranged from 0 to 52 , while in some of the above studies, the scores of the responses ranged from 1 to 5 and therefore the sum of the scores ranged from 13 to 65 . Given that a lower score indicates a better oral health-related quality of life, it seems that the participants had a relatively good quality of life.

The mean dmft index was $3.93 \pm 4.22$ in the present study, $1.54 \pm 2.47$ in a study by Segovia-Villanueva et al. in Mexico [25] and 2.1 \pm 3.1 in a study by Scarpelli et al. in Brazil [19]. Based on these findings, the children that

Table 2 ECOHIS responses in the survey of parents of 3-6 year-olds $(N=350)$

\begin{tabular}{|c|c|c|c|c|c|c|}
\hline Impacts & Never N (\%) & Hardly ever N (\%) & Occasionally N (\%) & Often N (\%) & Very often $\mathrm{N}(\%)$ & Don't know N (\%) \\
\hline \multicolumn{7}{|l|}{ Child impacts } \\
\hline Oral/ dental pain & $169(48.3)$ & $75(4.21)$ & $58(6.16)$ & $35(10)$ & $12(4.3)$ & $1(3.0)$ \\
\hline Difficulty drinking & $249(1.71)$ & $48(7.13)$ & $23(6.6)$ & $16(6.4)$ & $8(3.2)$ & $6(7.1)$ \\
\hline Difficulty eating & $204(3.58)$ & $66(9.18)$ & $36(3.10)$ & $22(3.6)$ & $16(6.4)$ & $6(7.1)$ \\
\hline Difficulty pronouncing words & $186(1.53)$ & $95(1.27)$ & $21(6)$ & $22(3.6)$ & $19(4.5)$ & $7(2)$ \\
\hline Missed preschool or school & $32(1.9)$ & $87(9.24)$ & $109(1.31)$ & $74(1.21)$ & $43(3.12)$ & $5(4.1)$ \\
\hline Trouble sleeping & $61(4.17)$ & $124(4.35)$ & $67(1.19)$ & $52(9.14)$ & $41(7.11)$ & $5(4.1)$ \\
\hline Irritable or frustrated & $94(9.26)$ & $117(4.33)$ & $73(9.20)$ & $41(7.11)$ & $21(6)$ & $4(1.1)$ \\
\hline Avoided smiling or laughing & $154(44)$ & $101(9.28)$ & $27(7.7)$ & $15(3.4)$ & $10(9.2)$ & $43(3.12)$ \\
\hline Avoided talking & $180(51.4)$ & $82(23.4)$ & $27(7.7)$ & $16(4.6)$ & $10(2.9)$ & $35(10)$ \\
\hline \multicolumn{7}{|l|}{ Parents impact } \\
\hline Been upset & $186(1.53)$ & $82(4.23)$ & $42(12)$ & $27(7.7)$ & $8(3.2)$ & $5(4.1)$ \\
\hline Felt guilty & $218(3.62)$ & $78(3.22)$ & $17(9.4)$ & $16(6.4)$ & $12(4.3)$ & $9(6.2)$ \\
\hline Time off from work and home & $240(6.68)$ & $45(9.12)$ & $41(7.11)$ & $12(4.3)$ & $8(3.2)$ & $4(1.1)$ \\
\hline Financial impact & $225(3.64)$ & $50(3.14)$ & $35(10)$ & $16(5.4)$ & $8(3.2)$ & $16(6.4)$ \\
\hline
\end{tabular}


Table 3 Impact of severity of caries on oral health-related quality of life-child and family impact section

\begin{tabular}{|c|c|c|c|c|c|}
\hline & $\mathrm{dmft}=0$ (Caries free) & $1 \leq \mathrm{dmft} \leq 5$ & $\mathrm{dmft} \geq 6$ & Total & $P$-value \\
\hline$N(\%)$ & $111(31.7 \%)$ & $136(38.9 \%)$ & $103(29.4 \%)$ & & \\
\hline ECOHIS (Child impact section) & $8.42 \pm 4.24$ & $9.66 \pm 5.30$ & $9.96 \pm 5.32$ & $9.36 \pm 5.02$ & $0.05^{*}$ \\
\hline ECOHIS (Family impact section) & $0.87 \pm 1.70$ & $2.72 \pm 3.25$ & $4.01 \pm 3.57$ & $2.52 \pm 3.20$ & $0.000^{*}$ \\
\hline Total & $9.29 \pm 5.04$ & $12.38 \pm 8.25$ & $13.97 \pm 8.89$ & $11.88 \pm 6.91$ & \\
\hline
\end{tabular}

* Calculated by Analysis of variance (ANOVA) test

participated in the present study had poorer dental health than the studies mentioned above. However, the recent study participants had better scores compared to the mean dmft index of Babol $(4.39 \pm 3.69)$ and Kerman $(5.6 \pm 3.6)$ preschool children $[22,23]$.

The present study results showed that with an increase in the mean dmft index, the total score of oral healthrelated quality of life increased as well. Our results are also in accordance with previous studies assessing the impact of dental caries on preschool children's OHRQoL [7-10]. This effect was greater on the parents' quality of life than that of children, indicating that the impact of children's oral health on parents' quality of life was greater than its effect on their quality of life. The reason for this finding is the importance of the children's health for parents. The parents are usually very sensitive to their children's health while a child might lack the perspective and insight; thus, the parents' quality of life would be more affected than that of children. Also, Sakaryali et al. study showed that both simple and severe conditions of ECC cause aesthetic and functional problems in children, and also deal the daily life of parents [8].

Moreover, in accordance with Paula et al. [26] study results the mean score of quality of life related to

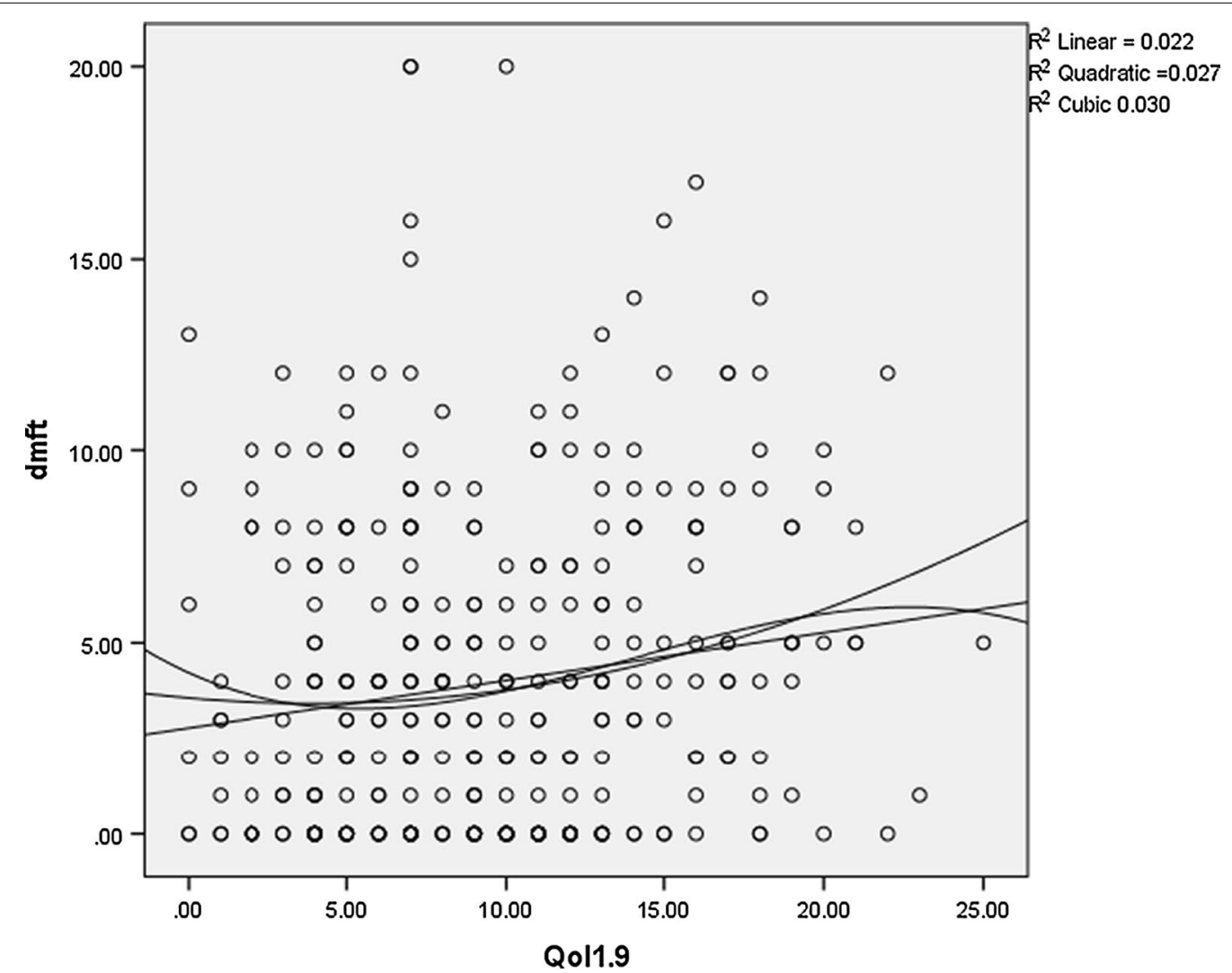

Fig. 1 Scatter plot of relation between dmft score and ECOHS in child impact 


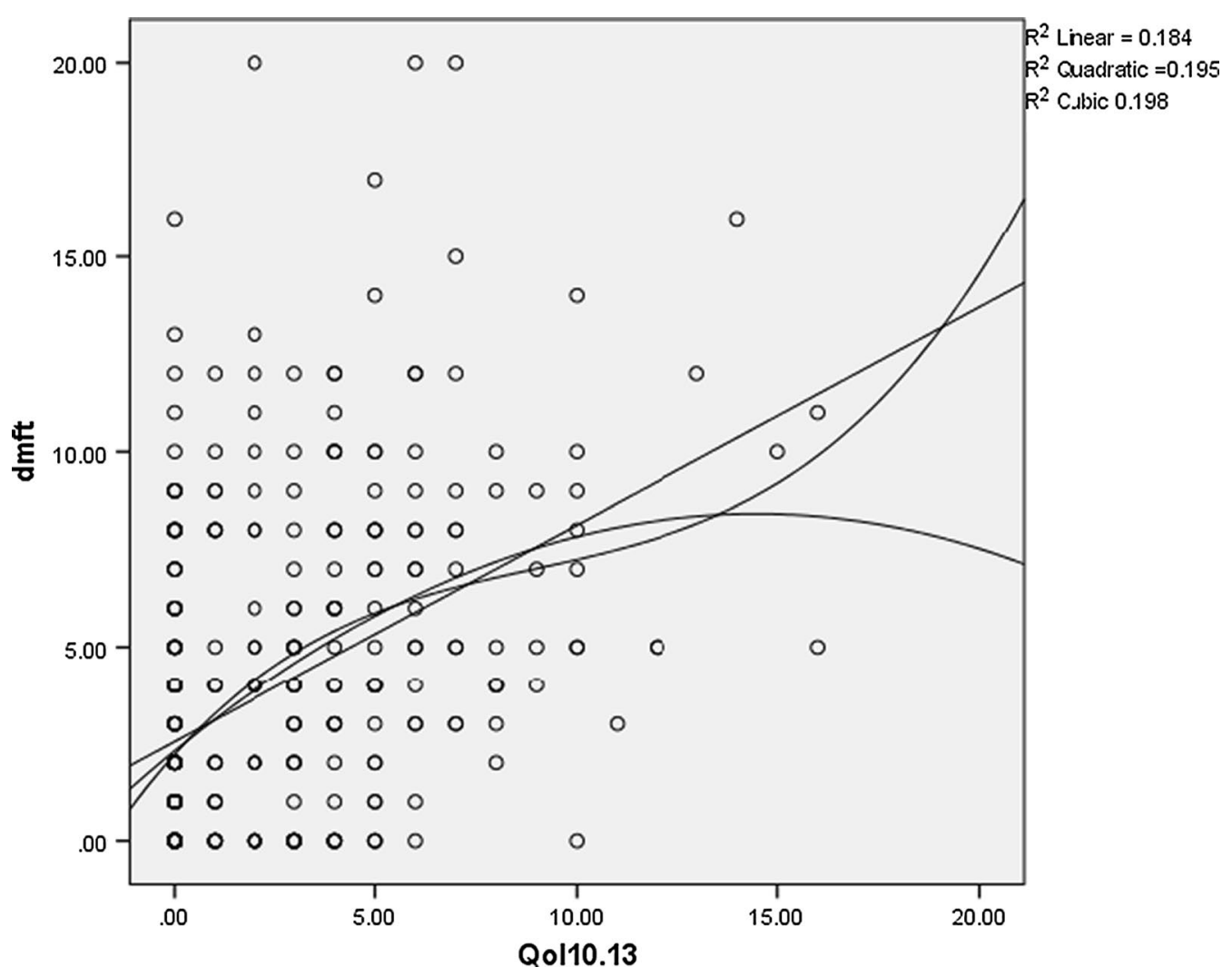

Fig. 2 Scatter plot of relation between dmft score and ECOHS in parents impact

children's oral health decreased with increased parents' education level. In Kumar et al. study, children of highincome and high-educated families had the better oral health-related quality of life [27]. Moreover, Nanayakkara found that children whose fathers were less educated had higher $\mathrm{dmft}$ scores, and a worse oral health-related quality of life [28]. Also, our results were in line with a Diaz et al. [7] study that found mother's education association with better preschool children's OHRQoL according to the Colombian ECOHIS. Considering the greater impact of the mother's education than father's education, which was also evident in the present study, it can be concluded that mothers play more effective role in improving the oral health-related quality of life in children. Sajjadi et al. [23] found that the OHRQoL only increased with an increase in mother's education while father's education had no significant relationship with the OHRQoL. It is usually expected that increased general and specialized knowledge may lead to increased health awareness, including oral health, or make parents more concerned about their children's oral health. On the other hand, lower education levels can lead to a lower income, unemployment, and poor working conditions, which may affect health-related behaviors and oral health status.
Also, similar to present study results, Nemati et al. [22] found no significant difference in the effect of oral health on quality of life between boys and girls. The reason is that the children evaluated in this study were very young (preschool), and gender differences in these children may have not yet influenced their understanding of the aesthetic aspects of oral health.

The results of this study showed a significant relationship between the mean score of oral health-related quality of life and age, which was consistent with the results of a study by Li et al. in which the quality of life had a significant relationship with age, i.e. an increase in age increased the impact of oral health on the quality of life [29]. Decreased oral health-related quality of life at higher ages is not unexpected because the teeth are more likely to become exposed to risk factors with age, and therefore the children will suffer more. In other words, problems such as chewing and speaking are more prominent at 5-6 years of age than 3 to 4 years; on the other hand, the persistence of the problem until higher ages will draw the parents' attention to it. Another finding of our study in line with the sakaryali et al. [8] study showed that the child's birth order 
in the family was not significantly correlated with the OHRQoL.

This study suffered from limitations; for example, some children did not cooperate for their dental examinations, some parents were unwilling to answer some questions, and some kindergarten authorities were not cooperative.

Moreover, the current study was accomplished only on kindergartens' preschool children. A further populationbased research would be required to OHRQoL assessment of preschool children living in the Gorgan city to confirm the present study results.

\section{Conclusion}

The present study showed that the oral health status of Gorgan preschool children affected their own and their parents' quality of life. The mean score of ECOHIS increased with the dmft index increase in children, indicating a significant relationship between the $\mathrm{dmft}$ and ECOHIS score.

These results can be used as proper resources to develop preventive policies and promote oral health in young children at a national level.

\section{Abbreviations}

dmft: decayed, missed, filled teeth; ECOHIS: Early Childhood Oral Health Impact Scale; OHRQOL: Oral health-related quality of life; WHO: World Health Organization.

\section{Acknowledgements}

The authors thank all of the parents for joining the study and for their support for completing questionnaires.

\section{Authors' contributions}

ER and MP conceived the study idea and led data collection. ER, MP, and AN created the study protocol and wrote original draft. MP, PA and AN led the writing- review \& editing. NB performed statistical tests. MP, ER, and PA interpreted the results. All authors read and approved the final manuscript.

\section{Funding}

Not applicable.

\section{Ethics approval and consent to participate}

The present study was approved by the Research Ethics Committee of Golestan University of Medical Sciences (IR.GOUMS.1397.166) and performed entirely following the Declaration of Helsinki.. Written Informed consent was obtained from parents before the study.

\section{Consent for publication}

Not applicable.

\section{Competing interests}

The authors declare no conflicts of interest.

\section{Availability of data and material}

The datasets used and/or analyzed during the current study are available from the corresponding author on reasonable request.

\section{Author details}

${ }^{1}$ Dental Research Center, Community Oral Health Department, School of Dentistry, Golestan University of Medical Sciences, Gorgan, Iran. ${ }^{2}$ Dental Research
Center, School of Dentistry, Golestan University of Medical Sciences, Gorgan, Iran. ${ }^{3}$ Dental Research Center, Orthodontics Department, School of Dentistry, Golestan University of Medical Sciences, Gorgan, Iran. ${ }^{4}$ Department of Dental Biomaterials, School of Dentistry, Shahid Beheshti University of Medical Sciences, Tehran, Iran. ${ }^{5}$ Department of Biostatistics and Epidemiology, School of Health, Golestan University of Medical Sciences, Gorgan, Iran.

Received: 6 October 2020 Accepted: 12 January 2021

Published online: 15 February 2021

\section{References}

1. Bonomi AE, Patrick DL, Bushnell DM, Martin M. Validation of the United States' version of the World Health Organization Quality of Life (WHOQOL) instrument. J Clin Epidemiol. 2000;53(1):1-12.

2. Organization WH. WHOQOL-BREF: introduction, administration, scoring and generic version of the assessment: field trial version, December 1996. Geneva: World Health Organization; 1996.

3. Daly B, Batchelor P, Treasure E, Watt R. Essential dental public health. Oxford: OUP; 2013.

4. Petersen PE. The World Oral Health Report 2003: continuous improvement of oral health in the 21 st century - the approach of the WHO Global Oral Health Programme. Commun Dent Oral Epidemiol. 2003;31:3-24

5. Abanto J, Tsakos G, Paiva SM, Carvalho TS, Raggio DP, Bönecker M. Impact of dental caries and trauma on quality of life among 5-to 6-year-old children: perceptions of parents and children. Commun Dent Oral Epidemiol. 2014:42(5):385-94

6. Gomes MC, de Almeida Pinto-Sarmento TC, de Brito Costa EMM, Martins CC, Granville-Garcia AF, Paiva SM. Impact of oral health conditions on the quality of life of preschool children and their families: a cross-sectional study. Health Qual Life Outcomes. 2014;12(1):55.

7. Díaz S, Mondol M, Peñate A, Puerta G, Boneckér M, Martins Paiva S, et al. Parental perceptions of impact of oral disorders on Colombian preschoolers' oral health-related quality of life. Acta Odontol Latinoam: AOL. 2018;31(1):23-31.

8. Sakaryali D, Bani M, Cinar C, Alacam A. Evaluation of the impact of early childhood caries, traumatic dental injury, and malocclusion on oral health-related quality of life for Turkish preschool children and families. Niger J Clin Pract. 2019;22(6):817-23.

9. Rajab LD, Abdullah RB. Impact of dental caries on the quality of life of preschool children and families in Amman, Jordan. Oral Health Prev Dent. 2020;18(1):571-82.

10. Mansoori S, Mehta A, Ansari MI. Factors associated with oral health related quality of life of children with severe-Early Childhood Caries. J Oral Biol Craniofac Res. 2019;9(3):222-5.

11. Sheiham A. Dental caries affects body weight, growth and quality of life in pre-school children. Br Dent J. 2006;201(10):625-6.

12. Gomes MC, Clementino MA, Pinto-Sarmento TC, Martins CC, GranvilleGarcia AF, Paiva SM. Association between parental guilt and oral health problems in preschool children: a hierarchical approach. BMC Public Health. 2014;14:854.

13. McGrath C, Broder H, Wilson-Genderson M. Assessing the impact of oral health on the life quality of children: implications for research and practice. Commun Dent Oral Epidemiol. 2004;32(2):81-5.

14. Barbosa TDS, Gavião MBD. Evaluation of the family impact scale for use in Brazil. J Appl Oral Sci. 2009;17(5):397-403.

15. Pahel BT, Rozier RG, Slade GD. Parental perceptions of children's oral health: the Early Childhood Oral Health Impact Scale (ECOHIS). Health Qual Life Outcomes. 2007:5(1):6.

16. Tesch FC, Oliveira BHD, Leão A. Semantic equivalence of the Brazilian version of the early childhood oral health impact scale. Cadernos de saude publica. 2008;24(8):1897-909.

17. Lee GH, McGrath C, Yiu CK, King NM. Translation and validation of a Chinese language version of the Early Childhood Oral Health Impact Scale (ECOHIS). Int J Pediatr Dent. 2009;19(6):399-405.

18. Lee GH, McGrath C, Yiu CK, King NM. Sensitivity and responsiveness of the Chinese ECOHIS to dental treatment under general anaesthesia. Commun Dent Oral Epidemiol. 2011;39(4):372-7. 
19. Scarpelli AC, Oliveira BH, Tesch FC, Leão AT, Pordeus IA, Paiva SM. Psychometric properties of the Brazilian version of the early childhood oral health impact scale (B-ECOHIS). BMC Oral Health. 2011;11(1):19.

20. Jabarifar S-E, Golkari A, IJadi MH, Jafarzadeh M, Khadem P. Validation of a Farsi version of the early childhood oral health impact scale (F-ECOHIS). BMC Oral Health. 2010;10(1):4

21. Amirabadi F, Rahimian-Imam S, Ramazani N, Saravani S, Kameli S. Evaluation of dental status and its association with oral health-related quality of life in preschool children in Zahedan City, Iran: a cross-sectional study. Middle East J Rehabil Health. 2017;4(1):1-5. e37043. https://doi. org/10.17795/mejrh-37043.

22. Nemati S, Ghasempour M, Khafri S. Impact of oral and dental health on quality of life in Iranian preschool children and their families. Electron Phys. 2016:8(11):3296

23. Sajadi FS, Pishbin L, Azhari SH, Moosazadeh M. Impact of oral and dental health on children's and parents' quality of life based on Early Childhood Oral Health Impact Scale (ECOHIS) Index. Int J Dent Sci Res. 2015;3(2):28-31

24. Shaghaghian S, Bahmani M, Amin M. Impact of oral hygiene on oral health-related quality of life of preschool children. Int J Dent Hyg. 2015;13(3):192-8.

25. Segovia-Villanueva A, Estrella-Rodríguez R, Medina-Solís CE, Maupomé $\mathrm{G}$. Dental caries experience and factors among preschoolers in
Southeastern Mexico: a brief communication. J Public Health Dent. 2006;66(2):88-91.

26. Paula JS, Leite IC, Almeida AB, Ambrosano GM, Pereira AC, Mialhe FL. The influence of oral health conditions, socioeconomic status and home environment factors on schoolchildren's self-perception of quality of life. Health Qual Life outcomes. 2012;10(1):6.

27. Kumar S, Kroon J, Lalloo R. A systematic review of the impact of parental socio-economic status and home environment characteristics on children's oral health related quality of life. Health Qual Life Outcomes. 2014;12(1):41.

28. Nanayakkara V, Renzaho A, Oldenburg B, Ekanayake L. Ethnic and socioeconomic disparities in oral health outcomes and quality of life among Sri Lankan preschoolers: a cross-sectional study. Int J Equity Health. 2013;12(1):89.

29. Li S, Veronneau J, Allison PJ. Validation of a French language version of the early childhood oral health impact scale (ECOHIS). Health Qual Life Outcomes. 2008;6(1):9.

\section{Publisher's Note}

Springer Nature remains neutral with regard to jurisdictional claims in published maps and institutional affiliations.
Ready to submit your research? Choose BMC and benefit from:

- fast, convenient online submission

- thorough peer review by experienced researchers in your field

- rapid publication on acceptance

- support for research data, including large and complex data types

- gold Open Access which fosters wider collaboration and increased citations

- maximum visibility for your research: over $100 \mathrm{M}$ website views per year

At BMC, research is always in progress.

Learn more biomedcentral.com/submissions 